\title{
La factura comercial y su proceso de cobro en el ordenamiento jurídico ecuatoriano
}

The commercial invoice and its collection process in the Ecuadorian legal regime

\author{
Ab. Robert Friend Macías, Mgtr. (Autor corresponsal) \\ Docente titular UEES
}

Ab. Emilia Arteta Acosta

Investigadora del Estudio Jurídico Bustamante \& Bustamante

Artículo Original (Revisión)

RFJ, No. 4, 2018, pp. 227-244, ISSN 2588-0837

RESUMEN: la presente investigación tiene como objetivo analizar el proceso legal de cobro de las facturas comerciales a través del método analítico descriptivo utilizado para estudiar el artículo 201 del Código de Comercio en concordancia con otras normas jurídicas que regulan la factura comercial negociable y la factura comercial simple, conocida comúnmente como comprobante de venta en el Ecuador. En ese sentido, se explicará cada tipo de factura según sus características y los diferentes mecanismos de cobro aplicables a cada una de ellas. El trabajo permitirá concluir que según el tipo de factura comercial que se requiera al cobro, la vía para hacer efectiva la obligación puede ser más simple o compleja. Finalmente, se propone un estudio de la legislación comparada que permite conocer la regulación de otros países respecto de este tipo de facturas y sus mecanismos de cobro.

PALABRAS CLAVE: deuda, derecho mercantil, procedimiento legal, factura comercial, cobro de facturas.

ABSTRACT: the objective of this research is to analyze the legal process of collection of commercial invoices through the descriptive analytical method used to study article 201 of the commercial code in accordance with other legal norms that regulate the negotiable commercial invoice and the simple commercial invoice commonly known as proof of sale in Ecuador. In that sense, each type of invoice 
will be explained according to its characteristics and the different collection mechanisms applicable to each one of them. The work will allow to conclude that depending on the type of commercial invoice required for collection, the way to make the obligation effective can be simpler or more complex. Finally, a study of comparative legislation is proposed that allows knowing the regulation of other countries regarding this type of invoices and their collection mechanisms.

KEY WORDS: debts, commercial law, legal procedure, commercial invoice, collect invoices.

\section{INTRODUCCIÓN}

Es conocido dentro del mundo jurídico y del comercio, que uno de los documentos que prueba un contrato mercantil es la factura. ¿Pero acaso sabemos con plenitud, qué tan fuerte es su poder probatorio en un juicio, los diferentes tipos de facturas que existen en el Ecuador o las dificultades que se pueden presentar al momento del cobro? El presente trabajo tiene como finalidad absolver estos tipos de dudas muy comunes al momento de reclamar la obligación mercantil.

La factura en el Ecuador ha tenido una significante evolución, es así, que existe la factura simple o factura comercial que cumple la función de comprobante de venta para fines contables y tributarios, la cual no garantiza el cobro efectivo de la obligación contraída por el deudor ni prueba de forma autónoma la misma dentro de un proceso judicial.

Así mismo, ante la necesidad de los acreedores para poder hacer efectiva la obligación contenida en la factura, el art. 201 del Código de Comercio reformado en el año 2014 publicada en el Registro Oficial No. 1202 del 20 de agosto de 1960, le otorgó la calidad de título valor y la denominación de factura comercial negociable al incluir en su literalidad, una cláusula cambiaria que obliga al deudor a reconocer anticipadamente la obligación mediante el manifiesto de haber recibido a su entera satisfacción los productos detallados en la misma, la cual también tiene otras características que le otorgan la calidad de título ejecutivo y pueden ser negociadas en el mercado de valores lo que permite que su cobro sea más rápido y eficaz.

El presente trabajo permitirá profundizar y desarrollar las diferencias entre estas facturas, aclarando las dudas que existen en la interpretación 
respecto de su naturaleza y sobre los mecanismos de cobro de las obligaciones que se hayan generado en la relación deudor - acreedor dentro de una operación mercantil en donde exista una factura de por medio.

\section{LA FACTURA COMERCIAL Y SU EVOLUCIÓN EN EL DE- RECHO ECUATORIANO}

El doctrinario Guillermo Cabanellas de la Torre define a la factura como una "Cuenta detallada, según número, peso, medida, clase o calidad y precio, de los artículos o productos de una operación mercantil." (Torre, 1993).

Una vez definido el término factura, es necesario comprender que cuando la factura forma parte de una operación cotidiana, repetitiva, pública y comercial se transforma en una factura comercial que puede ser una prueba más dentro de un proceso judicial para demostrar la existencia de un contrato mercantil.

Al ser este el tema central del presente análisis es de suma importancia conocer la evolución histórica de la factura dentro de la legislación en el Ecuador y adicionalmente detallar los tipos de facturas como se ha mencionado con anterioridad.

Pues bien, es conocido que el comercio como tal existe desde las primeras interacciones del ser humano cuando realizaba transacciones en las cuales se entregaba una cosa a cambio de otra. Pero, en la antigüedad no se registra puntualmente un documento que tenga el valor que tiene la factura comercial hoy en día. La factura se crea muchos años atrás con la necesidad de tener control sobre los sujetos pasivos y las relaciones comerciales que se generaban (Bustos, 2007). En el Ecuador la factura ha aparecido desde los años setenta aproximadamente, pero sin ser un documento de carácter obligatorio (Trávez, 2011). Anteriormente se la conocía únicamente como un título ejecutivo, mas no como un título valor, porque la misma carecía de características según lo establecido por el doctrinario Santiago Andrade Ubidia "En nuestro ordenamiento legal no le ha reconocido el carácter de Título Valor, menos todavía título cambiario." (Ubidia, 2006). Generando así una confusión, se propusieron varias reformas y cambios en la ley por existir falta de claridad en cuanto a las facturas. Por un lado, se presentó el proyecto de ley De las Compañías Financieras de Cesión de Facturas Comerciales, y Reformas al Código de Comercio 
De la Factura Comercial por Fernando Larrea Martínez (Trávez, 2011, pág. 13). Así mismo, existieron otros proyectos presentados ante el Congreso Nacional por varios diputados y personajes de la política ecuatoriana. Hasta la actual reforma del Código de Comercio, la cual sigue siendo confusa y no determina con claridad los distintos tipos de facturas existentes de tal manera que se proporcione facilidad para las relaciones mercantiles que se generan en el comercio ecuatoriano.

La Ley de Creación de la Red de Seguridad Financiera publicada en el Registro Oficial No. 498 del 2008 en su artículo 18 ordena que se incluya en el Código de Comercio de aquella época, un artículo donde se hable únicamente de la Factura Comercial Negociable con sus características a detalle. Dicha información ahora se encuentra plasmada dentro del artículo 201 del Código de Comercio, es un texto amplio compuesto por literales e incisos que desarrollan los tipos de factura comercial.

Se puede resumir de una manera sencilla que estos tipos de facturas comerciales contenidas dentro del código de comercio se clasifican en dos: factura comercial simple que cumple la función de comprobante de venta y la factura comercial negociable como título ejecutivo, las cuales se encuentran de manera expresa en el código de comercio en el artículo 201.

Luego de este preámbulo respecto de la factura y su evolución en el derecho ecuatoriano es preciso estudiar cada una de ellas con sus características y procesos de cobro.

\subsection{Factura como comprobante de venta}

La factura como comprobante de venta será desarrollada con definiciones doctrinarias, la ley y según lo establecido por el Servicio de Rentas Internas del Ecuador.

El Servicio de Rentas Internas establece que "son documentos previamente autorizados por el SRI, que respaldan las transacciones efectuadas por los contribuyentes en la transferencia de bienes o por la prestación de servicios o la realización de otras transacciones gravadas con tributos" (Servicio de Rentas Internas). Además, dentro del Reglamento de Comprobantes de Venta, Retención y Complementarios (2017) se determinan como sigue los comprobantes de venta: 
"Los siguientes documentos que acreditan la transferencia de bienes o la prestación de servicios o la realización de otras transacciones gravadas con tributos:
a) Facturas;
b) Notas de venta - RISE;
c) Liquidaciones de compra de bienes y prestación de servicios;
d) Tiquetes emitidos por máquinas registradoras;
e) Boletos o entradas a espectáculos públicos; y,
f) Otros documentos autorizados en el presente reglamento." (2017).

Dicho reglamento interesa dentro de este análisis porque demuestra que las facturas son comprobantes de venta, por ende, se puede deducir que las facturas son documentos que acreditan entrega de un bien o prestación de servicios como se menciona en el artículo primero del mencionado reglamento.

Herrera (2015) a su vez expone una definición de factura direccionada al contenido de la misma y al tipo de situación que se plantea: "La factura es el documento donde figuran el detalle y el precio de las mercancías vendidas o de los servicios prestados y que se entrega a quien paga dicho precio".

Mario Paz y Miño Cevallos (2011) establece en cambio, que estos documentos permiten que las personas puedan cumplir con sus respectivas obligaciones tributarias en cuanto a sus operaciones, al ser estas comerciales o no comerciales. Por último, es importante mencionar la definición de la factura expuesta por el doctrinario Manuel Ossorio (1974), quien establece que la factura es:

"Nota de contabilidad en la que se indica el detalle de las mercaderías entregadas, así como los trabajos ejecutados. El documento además de sus fines de contabilidad es entregado a quien ha de pagar las mercaderías o los trabajos, como justificación de su costo. En la factura suelen indicarse también la clase, la cantidad, la calidad y otros elementos relativos a la cosa facturada" (p. 402). 


\subsubsection{Características}

Este tipo de factura se caracteriza por ser un documento creado con la finalidad de dejar plasmada por escrito una transacción u operación económica. Es así que el art. 11 del Reglamento de Comprobantes de Venta, Retención y Complementarios (2017), establece que este tipo de facturas es utilizada en los siguientes casos:

“a) Desglosando el importe de los impuestos que graven la transacción, cuando el adquirente tenga derecho al uso de crédito tributario o sea consumidor final que utilice la factura como sustento de gastos personales;

b) Sin desglosar impuestos, en transacciones con consumidores finales; $y$,

c) Cuando se realicen operaciones de exportación."

Adicionalmente, el mismo cuerpo legal en su artículo 18 establece que existen ciertos requisitos que deben cumplirse para que las facturas cumplan con las características de un comprobante de venta y cómo deben ser llenadas.

Es de suma importancia tomar en cuenta que el artículo 201 del Código de Comercio (2014) establece que en cuanto a los reclamos de una factura como comprobante de venta se los debe realizar en los ocho días siguientes a la entrega del documento como tal. Dicho artículo establece precisamente que "No reclamándose contra el contenido de la factura, dentro de los ocho días siguientes a la entrega de ella, se tendrá por irrevocablemente aceptada." (Código de Comercio, 2014). Esto implica que, si la persona que recibe la factura como comprobante de venta no presenta un reclamo sobre el contenido de la misma en los 8 días posteriores, se da por entendido que dicha persona acepta la factura como se ha emitido, a menos que dentro de un proceso judicial a través de un acto propositivo, se demuestre lo contrario.

\subsubsection{Mecanismo Judicial de Cobro}

En cuanto al mecanismo judicial de cobro para este tipo de factura se debe aplicar el procedimiento monitoreo o el ordinario según corresponda. El Código Orgánico General de Procesos (2017) norma 
cómo se deberá llevar a cabo el proceso monitoreo, dentro del cual las facturas tienen un rol de suma importancia al ser la prueba más importante para ordenar el cumplimiento de la obligación.

Procederá la vía monitorea cuando "La persona que pretenda cobrar una deuda determinada de dinero, líquida, exigible y de plazo vencido, cuyo monto no exceda de cincuenta salarios básicos unificados del trabajador en general, que no conste en título ejecutivo" (COGEP, 2017). Es claro entonces que, si el monto de la factura excede los 50 salarios básicos unificados, la vía correspondiente para cobrar sería la ordinaria. Es importante resaltar que al ser la factura un documento individual, podría plantearse según la estrategia de defensa del actor, varios procesos de cobro por la vía monitoria que no excedan de la cuantía establecida en el COGEP.

El proceso monitoreo, será procedente cuando se pretenda cobrar una deuda determinada en dinero, líquida, exigible y de plazo vencido, cuyo monto no exceda de cincuenta salarios básicos unificados del trabajador en general, que no conste en título ejecutivo" (COGEP, 2017). La deuda que se busca cobrar por medio del proceso monitoreo deberá ser probada de cinco diversas formas establecidas en la legislación, entre ellas las facturas debidamente firmadas por el deudor de manera que se pueda probar la existencia de una deuda y adicionalmente la relación existente entre el deudor y el acreedor. (COGEP, 2017).

A diferencia del juicio ejecutivo, el procedimiento monitoreo inicia con la presentación del acto propositivo de la demanda que deberá cumplir con los requisitos establecidos en el cuerpo legal mencionado en líneas anteriores. Se deberá anunciar la prueba que en este caso será la misma factura de tal manera que el juzgador pueda apreciar con claridad todos los detalles de la deuda de la que se trata.

Dentro de este proceso, no es necesario el patrocinio de un abogado en el caso de que la deuda no exceda de los tres salarios básicos unificados del trabajador. (COGEP, 2017). Una vez presentada la demanda, el siguiente paso dentro del proceso monitoreo es que el juzgador califique la misma y otorgue un término de quince días para citar al demandado y que el mismo pague la deuda establecida en la demanda con la prueba adjunta. (COGEP, 2017). Posterior a la citación, existen dos posibilidades por parte del deudor. En primer lugar, este puede proceder con el pago de la deuda lo cual conducirá al archivo dicho proceso. En segundo lugar, el deudor puede oponerse a lo establecido en la deman- 
da. En el caso de darse una oposición, entonces se deberá llevar a cabo una audiencia única con dos fases, una de saneamiento y otra de juicio de la misma forma que se describió en el procedimiento ejecutivo.

En cuanto al problema probatorio de este tipo de factura, es preciso mencionar que la sola factura no sería prueba plena en el caso que la misma haya sido impugnada dentro del juicio. Por esta razón, en este caso particular de impugnación procesal, la sola factura no será prueba suficiente para ordenar el pago. Esta dificultad aumenta en el proceso ordinario en donde el deudor tiene más herramientas y mecanismos de defensa. En este punto es importante manifestar que coadyuva a la prueba, las guías de remisión en el caso de entrega de mercancías, comprobantes de retención, contratos celebrados entre las partes y cualquier otro medio de prueba aceptado dentro del ordenamiento jurídico para reconocer contratos mercantiles.

Finalmente se dicta sentencia al finalizar la audiencia única sobre la cual se puede solicitar su ampliación, aclaración y un recurso de apelación (COGEP, 2017). Es importante dar a conocer que en contra de la demanda del proceso monitorio solo caben determinados recursos tales como el de apelación además que cabe la ampliación y la aclaración. Pero, no cabe la reforma de la demanda y tampoco la reconvención.

\subsection{Factura Comercial Negociable}

El artículo 201 del Código de Comercio ecuatoriano la define como aquella "(..) que contengan una orden incondicional de pago, cuya aceptación sea suscrita por el comprador de bienes o su delegado, con la declaración expresa de que los ha recibido a su entera satisfacción" (Código de Comercio, 2014). A estas facturas les serán aplicables las disposiciones relativas al pagaré a la orden, en cuanto no sean incompatibles con su naturaleza, lo que les otorga la calidad de título valor.

En este punto, es necesario hacer el siguiente análisis. La factura comercial negociable no solo tiene como esencia ser un título valor, ya que la factura negociable que haya sido aceptada y cumpla los requisitos del código de comercio ecuatoriano y que además reúna los requisitos establecidos en las normas tributarias, adquiere la calidad de título ejecutivo. 
Para continuar con la descripción de la factura comercial negociable, es importante manifestar que son muy utilizadas en operaciones de factoring y operaciones conexas, de conformidad con las regulaciones que para el efecto emita la Junta de Política y Regulación Monetaria y Financiera. Especialmente el factoring, se vuelve más viable en cuanto al financiamiento de los proveedores, a través de entidades bancarias o empresas con este objeto. Lo cual, es lo que permite generar una diferencia entre la factura comercial negociable y la factura como comprobante de venta. Pero, para que se generen dichas operaciones de factoring y operaciones conexas, es de suma importancia que se genere una operación comercial. A su vez, se debe dar una necesidad por parte del comerciante para financiar el pago de una deuda que se produce por causa de la operación comercial mencionada.

\subsubsection{Características}

En su generalidad, la factura comercial negociable se caracteriza por ser un título valor, pero, como se lo ha tratado en líneas anteriores, por cumplir otros requisitos tributarios, adquiere calidad de título ejecutivo lo que obliga a que se regule un tratamiento diferente. La factura comercial negociable físicamente cuenta con tres ejemplares distribuidos de la siguiente manera: la primera y la segunda copia serán para el vendedor, la primera copia es la única transferible. Tanto el original como la segunda copia llevarán impresas la frase "no negociable". En este caso, para su presentación al cobro y pago, deberá presentarse obligatoriamente la primera copia. Esto implica que al vendedor le corresponde únicamente la copia original para que el mismo tenga la posibilidad de reclamar su derecho a cobro mediante la vía ejecutiva.

Adicionalmente al artículo analizado, es necesario mencionar que la factura comercial negociable puede ser emitida tanto por personas naturales como por personas jurídicas. Para poder ser emitidas, el requisito principal es que dichas personas deben dedicarse a actividades productivas que no tengan relación con servicios y deberán tener un plazo de emisión de hasta 360 días (Superintendencia de Compañias ). Es importante tomar en cuenta que este tipo de facturas constituyen un valor determinado el cual deberá negociarse. En caso de personas jurídicas deberá ser negociado en el Mercado de Valores tanto Bursátil como Extrabursátil. Así mismo, las personas naturales pueden negociar dicho valor establecido en la factura con "la inscripción en el Registro del Mercado de Valores y la de su emisor." (Superintendencia de 
Compañías). En cuanto al valor a negociarse, el Consejo Nacional de Valores determina que este no podrá exceder del noventa por ciento del valor total de la factura. (3)

De lo expresado hasta ahora, se demuestra la existencia de requisitos adicionales para que esta factura comercial negociable sea realmente un título ejecutivo. Además, se puede notar que todo gira en torno al pago de un monto de dinero determinado, donde las personas involucradas en dicho objeto deben ser absolutamente capaces en cuanto a la obligación que deben cumplir o exigir.

\subsubsection{Mecanismo judicial de cobro}

Como se ha mencionado en líneas anteriores, "les son aplicables las disposiciones relativas al pagaré a la orden." (Pago de Valores, 2015). Esto implica que, para exigir el pago adeudado, se debe acudir al procedimiento ejecutivo y cuando prescribe la acción ejecutiva, se debe proceder a la vía ordinaria. Así mismo, cuando esta factura comercial negociable no reúne los requisitos para ser considerada como título ejecutivo, se debe iniciar la vía monitorea u ordinaria según corresponda.

En este punto es adecuado resaltar que la vaguedad en la redacción del art. 201 del Código de Comercio, provoca inseguridad jurídica ya que se puede interpretar que existen otras facturas comerciales negociables que no alcanzan a ser títulos ejecutivos y solo adquieren calidad de título valor.

Ahora bien, centrándonos nuevamente en el procedimiento de cobro de una factura comercial negociable como título ejecutivo, el artículo 347 del COGEP, establece que "son títulos ejecutivos siempre que contengan obligaciones de dar o hacer:" (2017). El procedimiento mencionado será procedente cuando la obligación contenida en el título sea clara, pura, determinada y actualmente exigible. Es importante, además, tomar en cuenta que para que sea admisible el procedimiento ejecutivo, debe cumplir con los requisitos generales de demanda establecidos en el Código Orgánico General de Procesos y adicionalmente deberá la demanda estar acompañada del título ejecutivo correspondiente. Es decir, se perfecciona la obligación de dar o hacer por la existencia de una relación comercial donde una de las partes debe cumplir o exigir dicha obligación a la otra parte involucrada. 
El proceso ejecutivo se inicia con la demanda que se ha especificado anteriormente, la cual deberá ser calificada en un término de tres días. Una vez calificada la demanda, el demandado, al contestar la misma, tendrá cuatro opciones en cuanto al proceso ejecutivo siendo estas opciones las siguientes:

"1. Pagar o cumplir con la obligación.

2. Formular oposición acompañando la prueba conforme con lo previsto en este Código.

3. Rendir caución con el objeto de suspender la providencia preventiva dictada, lo cual podrá hacer en cualquier momento del proceso, hasta antes de la sentencia.

4. Reconvenir al actor con otro título ejecutivo." (COGEP, 2017).

Una vez planteada una de estas cuatro opciones, entonces se llevará a cabo la audiencia única que a su vez tiene dos partes principales, como se mencionó anteriormente, estas dos partes son la primera de saneamiento y la segunda la etapa de juicio. Dentro de la primera parte de la audiencia se tratarán puntos tales como saneamiento, conciliación, entre otros; la segunda parte trata los alegatos y pruebas de las partes en cuanto a la obligación en cuestión. Una vez concluidas estas dos partes de la audiencia única, entonces se dictará sentencia la cual tiene un efecto no suspensivo. Es importante adicionalmente mencionar que luego de concluida la segunda instancia en el procedimiento ejecutivo, no existe posibilidad de interponer el recurso de casación. (COGEP, 2017).

\section{LEGISLACIÓN COMPARADA CON RELACIÓN A LAS FACTURAS}

Para poder cerrar este análisis y dar conclusiones al respecto de las facturas dentro de la legislación ecuatoriana, es importante estudiar y comparar lo que otras legislaciones proponen respecto del mismo tema. Así mismo es interesante observar cual es el mecanismo o procedimiento que se lleva a cabo en otros países en cuanto a los distintos tipos de facturas. Por esta razón, a continuación, se plasmará todo lo referente a las facturas en Colombia y Chile en relación con lo estudiado anteriormente de las facturas en el Ecuador. 
Colombia, como todos los demás países de América Latina, incorporó dentro de su legislación los títulos valores en virtud de la Ley Uniforme de Título Valores para América Latina de 1967. Se crea en Colombia la Ley 1231 la cual ha sido reformada en reiteradas ocasiones, de tal forma que vaya facilitando el comercio y las operaciones del mismo. Así mismo, se fueron creando distintas leyes como por ejemplo el Estatuto Tributario, el Código de Comercio, entre otros con la finalidad de cubrir todos los aspectos legales referentes a las facturas en Colombia (Orozco, 2009).

Pues bien, anteriormente en Colombia existían varios tipos de facturas tal como en Ecuador. Dichos tipos de facturas eran "Facturas de Venta, Facturas Cambiarias de Compraventa, Facturas Electrónicas y documentos equivalentes a Factura de Venta" (Romero Restrepo , Fajardo Calderón , \& Vélez Romero, 2010). Entonces es importante brevemente explicar cada uno de estos tipos de facturas. En cuanto a la factura de venta, la misma "se expedirá en las operaciones que se realicen con comerciantes, importadores o prestadores de servicios, o en las ventas a consumidores finales" (DIAN, 2007). En cuanto a la Factura Cambiaria de Compraventa, César Luis Correa Zúñiga cita al autor Alberto Gómez Gómez quien establece que “(...) es un documento formalista que legitima el ejercicio del derecho literal y autónomo que en él se incorpora, de contenido crediticio, originado siempre en un contrato de compraventa de mercadería (...)" (Zúñiga, 2014, pág. 58). Por último, la Factura Electrónica, se define como "un documento computacional que soporta una transacción de venta de bienes o prestación de servicios" (Calvo \& Chacón Jiménez , 2011). Tomando en cuenta todas las definiciones planteadas por distintos tratadistas respecto los diferentes tipos de facturas, se puede observar que la factura cambiaria es la más similar a la factura comercial negociable que existe en la legislación ecuatoriana.

Hoy en día en Colombia, el tema de las facturas ha evolucionado, debido a que se han unificado en la Ley 1231 todos los tipos de facturas dándoles la calidad de títulos valores (Romero Restrepo , Fajardo Calderón , \& Vélez Romero, 2010). Entonces, actualmente dentro de la legislación colombiana solo se encuentran la factura comercial simple y la factura comercial como título valor. En el caso de la factura comercial simple es: 
"Aquella que el comprador puede exigir al vendedor donde conste por lo menos el precio y pago total y que debe expedir y entregar el vendedor de bienes o el prestador de servicios cuando la negociación se hace de contado; en tal caso simplemente no hay título valor y esta factura no puede ponerse a circular." (Romero Restrepo, Fajardo Calderón \& Vélez Romero, 2010).

En el caso de la factura comercial como título valor, los doctrinarios la definen como aquella que debe cumplir con los requisitos establecido en la Ley 1231. En caso de no cumplirlos, entonces no será considerada como factura unificada y existe una excepción siendo esta la factura cambiaria de transporte (Vásquez, 2008).

Una vez analizada la legislación colombiana, entonces se procederá al análisis respecto de las facturas en la legislación de Chile. En cuanto a esta legislación, la factura se define en base "a consecuencia de relaciones contractuales de compraventa o de prestación de servicios $\mathrm{u}$ otras, que la ley asimila a aquellas y en muchas ocasiones, es el único documento que refleja estos actos y las obligaciones pendientes de pago, todo lo cual tiene un evidente valor tributario, comercial y contractual" (Puga, 2016). Esto da entender que existe un solo tipo de factura en la legislación y a estas se les puede otorgar un mérito ejecutivo. Dicho mérito se genera en caso de existir obligaciones de dar, hacer o no hacer. Siendo esta el tipo de factura que tiene relación con la factura comercial negociable legislada en Ecuador (Puga, 2016).

\section{PROPUESTA DE REFORMA DEL ARTÍCULO 201 DEL CÓ- DIGO DE COMERCIO}

Luego del estudio efectuado a los tipos de factura en la legislación ecuatoriana, se puede evidenciar que subsiste la problemática que se ha desencadenado muchos años atrás, a pesar que el artículo 201 del Código de Comercio fue reformado primero por el artículo 18 de la Ley No. 0 , publicada en el Registro Oficial Suplemento 498 de 31 de diciembre del 2008 y después reformada por la ley No. 0, publicada en el Registro Oficial Suplemento 332 de 12 de septiembre del 2014, donde se incluyó en el ordenamiento jurídico ecuatoriano a la factura comercial negociable.

En ese sentido, se propone realizar una reforma al Código de Comercio, precisamente al artículo 201. Este artículo debería abarcar todos los distintos tipos de facturas, definiéndolos de manera clara para 
poder diferenciarlas unas de otras. Además, sería pertinente incluir dentro de dicho artículo cuál es el procedimiento de cada uno de los documentos en cuestión y los mecanismos o vías procesales de cobro.

Esta reforma es necesaria también porque la factura simple no es un elemento probatorio suficiente dentro de un proceso, entonces la solución sería incluir dentro de los tipos de facturas, la llamada factura cambiaria sin los requisitos que tiene la factura comercial negociable, para que así exista otra factura comercial sin la calidad de título ejecutivo pero que pueda considerársela como título valor con la sola inclusión de la cláusula cambiaria que en su parte literal deberá decir "debo y pagaré a la orden de...", a fin de transformar a la factura simple en "pagaré a la orden y exigir su pago en acción cambiaria". Además, para este nuevo tipo de factura cambiaria, se debería cambiar su denominación de "Factura de Venta" y no "Factura de Compraventa" para transacciones que involucren plazos de vencimiento de pago.

\section{CONCLUSIONES}

Se ha evidenciado que la factura comercial cumple varias funciones como ser comprobante de venta para fines tributarios y también para fines bursátiles como en los procesos de factoring.

A pesar de que el artículo 201 del código de comercio ecuatoriano fue reformado primero por el artículo 18 de la Ley No. 0, publicada en el Registro Oficial Suplemento 498 de 31 de diciembre del 2008 y después reformado por la Ley No. 0, publicada en el Registro Oficial Suplemento 332 de 12 de septiembre del 2014, donde se incluyó en el ordenamiento jurídico ecuatoriano a la factura comercial negociable, no soluciona el problema probatorio dentro los procesos de cobro de la factura comercial simple que es la más utilizada por los comerciantes.

No existe una definición clara y precisa de los distintos tipos de facturas que se reconocen en el artículo 201 del Código de Comercio en el Ecuador, lo que provoca inseguridad jurídica en razón de que se desprende de su redacción, la existencia no solo de las dos facturas analizadas, sino también de una tercera factura que podría denominársela como factura cambiaria, que justifica la propuesta de reforma planteada.

Como consecuencia de la conclusión anterior, se determina que hay un vacío legal para diferenciar la factura comercial negociable como 
título ejecutivo con otro tipo de factura comercial que podría ser considerada como título valor cuando esta última, no reúna los requisitos tributarios y requisitos que regulan el mercado de valores.

La entrada en vigencia del COGEP y la incorporación del procedimiento monitoreo para el cobro de obligaciones, no ha permitido que el proceso de cobro de las facturas comerciales simples se facilite por la deficiencia probatoria de la misma, más bien, ha resultado complejo cuando el cobro de estas facturas exceden los 50 salarios básicos unificados lo que obliga por Ley, dar paso a un procedimiento ordinario.

El proceso de cobro de una factura simple también se complica en nuestra legislación cuando el deudor es una persona natural en razón que al no ser la factura prueba suficiente, las pruebas adicionales anunciadas y prácticas dentro del proceso deberían ser otras como las guías de remisión o un contrato mercantil.

Se concluye finalmente, que la legislación colombiana luego de varias reformas en su ordenamiento jurídico da un trato un parecido a la factura como en la legislación ecuatoriana, pero con la diferencia que se reconoce a la factura cambiaria para temas de transporte.

\section{REFERENCIAS BIBLIOGRÁFICAS}

Código Orgánico Integral Penal (2014).

Código de Comercio (2014) Obtenido de Lexis: http://www.silec. com.ec/Webtools/LexisFinder/DocumentVisualizer/FullDocumentVisualizerPDF.aspx?id=MERCANTI-CODIGO_DE_COMERCIO

Pago de Valores, 17711-2013-0829 (Función Judicial 31 de julio de 2015).

COGEP (2017). Obtenido de LEXIS: http://www.silec.com.ec/Webtools/LexisFinder/DocumentVisualizer/FullDocumentVisualizerPDF.aspx?id=CIVIL-CODIGO_ORGANICO_GENERAL_DE_PROCESOS_COGEP 
Reglamento de Comprobantes de Venta, Retención y Complementarios (2017). Obtenido de Lexis: http://www.silec.com.ec/Webtools/ LexisFinder/DocumentVisualizer/FullDocumentVisualizerPDF. aspx?id=TRIBUTAR-REGLAMENTO_DE_COMPROBANTES_DE_ VENTA_RETENCION_Y_COMPLEMENTARIOS

Bustos, J. (2007). El Impuesto al Valor Agregado y el Régimen de Facturación en el Impuesto a la Renta. Quito, Ecuador: Cevallos.

Cabanellas, G. (1993). Diccionario Jurídico Elemental. Guatemala: Heliastra S.R.L.

Calvo, J. M. y Chacón Jiménez , A.V. (2011). La Factura Electrónica en Colombia: visión integral. 19. Colombia: Revista Punto de Vista.

Cedillo, F. V. (2013). Derecho Ecuador. Obtenido de https://www2. derechoecuador.com/procesos-de-ejecucion-0

Cevallos, M. P. (2011). Títulos Valor: otro Enfoque. Quito: PPL Impresores.

Dávila, C. (2006). Proyecto de Código de Comercio.

DIAN. (2007). Dirección de Impuestos y Aduanas Nacionales. Obtenido de Requisitos de la Factura y Documentos equivalentes 2007: http://www.dian.gov.co/descargas/plegables/factura2.pdf

Herrera, M. (2015). La Factura. Obtenido de http://contenidofactura2015.blogspot.com/2015/01/concepto-caracteristicas-y-requisitos.html

Martínez, E. V. (1983). La Factura Cambiaria. Obtenido de http://recursosbiblio.url.edu.gt/publicjlg/biblio_sin_paredes/fac_juri/fac_Ca.pdf

Orozco, M. M. (2009). Memorando No. 690. Obtenido de Universidad Nacional de Colombia: http://www.legal.unal.edu.co/sisjurun/normas/Norma1.jsp? $\mathrm{i}=42565$

Puga, A. P. (2016). Dialnet. Obtenido de Alcance Juridico de la factura como título de circulación mercantil : http://www.scielo.cl/scielo. php?script=sci_arttext\&pid=S0718-68512016000100005 
Romero Restrepo, M., Fajardo Calderón, C.L. y Vélez Romero, C. A. (2010). Aspectos Jurídicos y Tributarios de la Factura Como Título Valor. 8(13), 209-230. Bogotá, Colombia: Criterio Libre.

Servicio de Rentas Internas. (s.f.). SRI. Obtenido de http://www.sri. gob.ec/web/guest/comprobantes-de-venta

Superintendencia de Compañías . (s.f.). Aspectos Básicos de la Negociación de las Facturas Comerciales Negociables. Obtenido de Guía Práctica: file://C:/Users/earteta/Downloads/Factura\%20Comercial\%20 Negociable\%20-\%20Aspectos\%20B\%C3\%A1sicos.pdf

Torre, G. C. (1993). Diccionario Jurídico Elemental. Obtenido de SCRIBD: https: //es .scribd. com /doc/ 27671641/ Diccionario-Juridico-de-Guillermo-cabanellas-de-Torres

Trávez, V. A. (2011). La Nueva Naturaleza Jurídica de la Factura en Ecuador. Quito, Ecuador: Universidad de las Américas.

Ubidia, S. A. (2006). Los Títulos Valor en el Derecho Ecuatoriano. Quito: Andrade \& Asociados.

Vásquez, M. Á. (2008). Ánalisis de la ley 1231 de 2008. Obtenido de https://www.gerencie.com/analisis-de-la-ley-1231-de-2008.html

Zuñiga, C. L. (2014). La Factura Negociable y sus Limitaciones a la Libre Circulación. Obtenido de file:///Users/EmiAr/Downloads/CORREA_ZUNIGA_CESAR_FACTURA_NEGOCIABLE.pdf 
Recibido: 12 de septiembre de 2018

Aceptado: 25 de noviembre de 2018

Ab. Robert Friend Macías, Mgtr:Docente Titular UEES

Correo electrónico: robesrtfriend@uees.edu.ec

Ab. Emilia Arteta Acosta: Investigadora del Estudio Jurídico Bustamante \& Bustamante

Correo electrónico: emiarteta18@hotmail.com 